\title{
Author Correction: Gastroesophageal reflux GWAS identifies risk loci that also associate with subsequent severe esophageal diseases
}

Jiyuan An, Puya Gharahkhani (D, Matthew H. Law (D), Jue-Sheng Ong (1), Xikun Han (1), Catherine M. Olsen (1), Rachel E. Neale, John Lai, Tom L. Vaughan, Ines Gockel, René Thieme, Anne C. Böhmer (D), Janusz Jankowski, Rebecca C. Fitzgerald (D, Johannes Schumacher, Claire Palles, BEACON, 23andMe Research Team, David C. Whiteman \& Stuart MacGregor (D)

Correction to: Nature Communications https://doi.org/10.1038/s41467-019-11968-2, published online 16 September 2019.

The original version of this Article omitted from the author list the 10th and 11th authors, Ines Gockel and René Thieme, who are from the Department of Visceral, Transplant, Thoracic and Vascular Surgery, University Hospital of Leipzig, Leipzig, Germany. Consequently, their initials were added to the Author Contributions as having 'contributed to the data collection and contributed to genotyping.' This has been corrected in both the PDF and HTML versions of the Article.

Published online: 04 December 2019

\section{BEACON}

Marilie D. Gammon, Douglas A. Corley, Nicholas J. Shaheen, Nigel C. Bird, Laura J. Hardie, Liam J. Murray, Brian J. Reid, Wong-Ho Chow, Harvey A. Risch, Weimin Ye, Geoffrey Liu, Yvonne Romero, Leslie Bernstein \& Anna H. Wu

\footnotetext{
(c) (i) Open Access This article is licensed under a Creative Commons Attribution 4.0 International License, which permits use, sharing, adaptation, distribution and reproduction in any medium or format, as long as you give appropriate credit to the original author(s) and the source, provide a link to the Creative Commons license, and indicate if changes were made. The images or other third party material in this article are included in the article's Creative Commons license, unless indicated otherwise in a credit line to the material. If material is not included in the article's Creative Commons license and your intended use is not permitted by statutory regulation or exceeds the permitted use, you will need to obtain permission directly from the copyright holder. To view a copy of this license, visit http://creativecommons.org/licenses/by/4.0/.
}

(C) The Author(s) 2019 